\title{
The large database analysis: A useful "Band-Aid" solution
}

\author{
Sai Yendamuri, MD, FACS
}

\author{
From the Department of Thoracic Surgery, Roswell Park Cancer Institute, Buffalo, NY. \\ Disclosures: Author has nothing to disclose with regard to commercial support. \\ Received for publication Nov 26, 2017; accepted for publication Dec 4, 2017; available ahead of print Jan 20, \\ 2018. \\ Address for reprints: Sai Yendamuri, MD, FACS, Department of Thoracic Surgery, Roswell Park Cancer Institute, \\ Buffalo, NY 14263 (E-mail: sai.yendamuri@roswellpark.org). \\ J Thorac Cardiovasc Surg 2018;155:1803 \\ $0022-5223 / \$ 36.00$ \\ Copyright (C 2017 by The American Association for Thoracic Surgery \\ https://doi.org/10.1016/j.jtcvs.2017.12.009
}

The gold standard for clinical evidence is a meta-analysis of several randomized, controlled trials. Evidence of this level is rare, however, for most clinical issues facing the practicing thoracic surgeon. Reasons for this include, but are not limited to, the immense cost of randomized, controlled trials, the difficulty in enrolling patients with an uncommon pathology, the absence of equipoise of the treating physician, and competing trials for the same population. The only recourse available to the investigative physician is thus the use of retrospective data, with all its attendant bias. In the selection of sources of retrospective data, some judgment bodes well for the utility of the conclusions drawn. One of the many sources available for the conduct of such a study is the National Cancer Database (NCDB), a retrospective multicenter database that documents important variables in the treatment of a large proportion of cancers in the United States.

The merits and limitations of the use of the NCDB are well described elsewhere. ${ }^{1}$ Situations in which the NCDB is particularly useful, however, include the following:

1. The target population is uncommon, but easily and robustly identifiable in terms of location, histologic type, or other easily measured clinical characteristics.

2. There is enough variability in the clinical management of the condition that sufficient patients exist in each treatment group.

3. The overall survival is indicative of the oncologic outcome (because recurrence data and disease-free survival are not presented in the NCDB).

4. If multimodality treatment is used, treatment regimens are fairly standardized.

5. It is unlikely that the question asked will be studied in a randomized, controlled trial.

The question that the study by Drake and colleagues ${ }^{2}$ in this issue of the Journal asks fits all these criteria and is therefore eminently suitable to be answered by analysis of NCDB data. It is unlikely that the benefit of adjuvant therapy for the treatment of non-small cell lung cancer invading the chest wall will be the subject of a randomized,

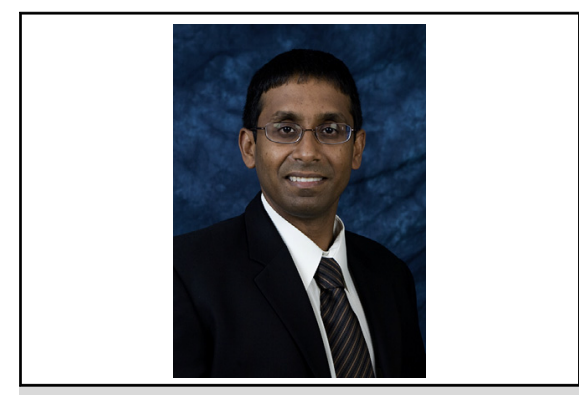

Sai Yendamuri, MD, FACS

Central Message

National Cancer Database analyses, although not perfect, are useful tools to analyze specific issues germane to thoracic surgeons.

See Article page 1794.

controlled trial or that a singe institution will have enough of these patients treated with different regimens to make any other way of studying this question credible. On the other hand, although some method of controlling for bias is reasonable, this is limited to the data available. Selection bias, which is substantial in a database such as the NCDB, cannot be accounted for with the limited comorbidity data available. This remains a concern and limits the strength of the conclusions that can be drawn.

Critics of such an approach may dismiss these investigations as "Band-Aid" solutions. Malcolm Gladwell, ${ }^{3}$ however, cautions us that "that phrase should not be considered a term of disparagement. The Band-Aid is an inexpensive, convenient, and remarkably versatile solution to an astonishing array of problems. In their history, BandAids have probably allowed millions of people to keep working or playing tennis or cooking or walking when they would otherwise have had to stop. The Band-Aid solution is actually the best kind of solution because it involves solving a problem with the minimum amount of effort and time and cost."

\section{References}

1. Boffa DJ, Rosen JE, Mallin K, Loomis A, Gay G, Palis B, et al. Using the National Cancer Database for outcomes research: a review. JAMA Oncol. 2017;3:1722-8

2. Drake JA, Sullivan JL, Weksler B. Adjuvant chemotherapy improves survival in patients with completely resected T3N0 non-small cell lung cancer invading the chest wall. J Thorac Cardiovasc Surg. 2018;155:1794-802.

3. Gladwell M. The Tipping Point: How Little Things Can Make a Big Difference. 1st paperback ed. Boston: Back Bay Books; 2002. p 256. 